\title{
CICLO PROJECT "STRENGTHENING THE CIRCULAR ECONOMY SKILLS OF THE EU LABOUR SERVICES” - CIRCULAR ECONOMY IN PORTUGAL
}

\author{
M. Potes Barbas, N. Lopes, M. José \\ Instituto Politécnico de Santarém - Escola Superior de Educação (PORTUGAL)
}

\begin{abstract}
The CICLO project "Strengthening the circular economy skills of the EU Labour Services" is an Erasmus + KA2 that aims to improve and multiply the opportunities for improvement and requalification of long-term and low-skilled unemployed workers, in the field of evolution the circular economy market, through innovative vocational education and training (VET) tools and pedagogies, accompanied by skills assessment, recognition and validation methods.
\end{abstract}

To that end, the CICLO project envisages the development of an interactive labor market and online skills ecosystem, geared to the needs of the circular economy, providing a training package for employed and unemployed people in order to equip them with basic skills related to recycling, opportunities for management, reuse and remanufacturing and service development (instead of products).

The project is divided into five different intellectual outputs, comprising the following products: Cos Ecosystem of Circular Economy Skills and Methodological Framework; Cur CICLO curriculum and VET toolbox for key skills acquisition resources; Platform Multifunctional and Interactive Platform; Assessment Skills assessment, validation and recognition tools and Package Adaptation and policy package.

Through these five phases, the project will offer a course of action to combat low levels of circular economy skills among long-term unemployed and low-skilled workers, while enabling unemployed workers and people to become creators of their own career through the economy market Circular. The project will also maximize your employability opportunities, enhance the development of critical media literacy skills and competences in VET and provide innovative VET teaching methods, best practice guidelines and strategies for using digital tools and innovative learning environments.

The project is managed by a consortium of 8 European partners, covering a wide range of knowledge related to the scope and objectives of the project, also having a pan-European scope in its activities, with the Polytechnic Institute of Santarém being one of these partners.

With this article, we intend, through the impulse of the project, to give Portugal's vision on the great theme of the CICLO project, the Circular Economy. We will focus on four topics: what is the Circular Economy, strategies adopted by Portugal, surrounding policies and business examples that have adopted this model.

Keywords: Circular Economy, Portugal, Strategies, Policies.

\section{INTRODUCTION}

The project "boosting the CIrcular eConomy skills of the EU services Labor fOrce" is a Erasmus+ KA2 project that aims to upgrade and multiply the opportunities for up-skilling and re-skilling of long term unemployed and low-skilled workers, in the field of evolving circular economy market, via innovative VET tools and pedagogies, accompanied by skills acquisition assessment, recognition and validation methods.

For this purpose, the CICLO project envisions the development of an interactive, needs-oriented online Circular Economy labor market ecosystem and skills mapping, providing a training package for employed and unemployed persons in order to equip them with basic circular economy jobs skills related to recycling management, reuse and remanufacturing opportunities, and sovietisation (services instead of products) development.

The project is divided in five different Intellectual Outputs comprising the following products:

- Circular Economy Skills Ecosystem and Methodological Framework; 
- CICLO Curriculum and VET Toolbox of Key Skills Acquisition Resources;

- Multifunctional and Interactive Platform;

- Skills Assessment, Validation and Recognition Tools;

- Adaption and Policy Package.

Through these five phases, the project will offer a course of action to combat low levels of circular economy skills among long-term unemployed and low-skilled workers, while empowering workers and unemployed persons to become creators of their own career via the circular economy market. The project will also maximize their employability opportunities, enhance the development of critical media literacy skills and competences in VET and provide innovative VET pedagogical methods, best practice guidelines, and strategies towards the use of digital tools and innovative learning environments.

The project is managed by a consortium of 8 partners from 7 European countries, covering a wide range of expertise related to the scope and the aims of the project, having a Pan-European outreach as well in their activities. The partners are:

- CEKOV - Nezisková Organizácia Centrum Kontinuálneho Vzdelávania (Slovakia),

- CSI - Center for Social Innovation LTD (Cyprus),

- Magenta Consultoría Projects SLU (Spain),

- Stimmuli For Social Change (Greece),

- Fondo Provinciale Milanese per la Cooperazione Internazionale (Italy),

- Instituto Politecnico de Santarem (Portugal),

- Prism - Promozioe Internazionale Sicilia-Mondo (Italy), and

- MEATH Community Rural and Social Development Partnership Limited (Ireland).

\section{STATE OF THE ART}

The concept of Circular Economy is intrinsically linked to the concept of Green Economy and sustainable development. It started developing around the 1970 s as an alternative to the linear economic model aiming at a low environmental impact by minimizing waste, turning goods into resources for others through re-use, re-manufacture, re-cycle, waste reduction and other practices (Taranic, Behrens, \& Topi, 2016). There are, however, different definitions of circular economy used in scientific literature and professional journals because this concept has been researched and applied by diverse groups of researchers and professionals (Kirchherr, Reike, \& Hekkert, Conceptualizing the circular economy: An analysis of 114 definitions, 2017) with different focuses and different goals.

The European Parliament (Parliament, 2018) describes Circular Economy as: "a model of production and consumption, which involves sharing, leasing, reusing, repairing, refurbishing and recycling existing materials and products as long as possible".

The Ellen Macarthur Foundation (Foundation, 2017)", one of the most prestigious foundations working to boost circular economy in Europe and worldwide, defines circular economy as "a restorative and regenerative system which intends to achieve that products, resources and components keep their utility and value at all times".

For them, the concept of circular economy recognizes the importance of the economy needing to work effectively at all scales - for large and small businesses, for organizations and individuals, globally and locally. Transitioning to a circular economy does not only amount to adjustments aimed at reducing the negative impacts of the linear economy. Rather, it represents a systemic shift that builds long-term resilience, generates business and economic opportunities, and provides environmental and societal benefits.

The Sustainability Guide, (Guide, 2017) developed by SVID and Green Leap at KTH Royal Institute of Technology in Stockholm, within the project EcoDesign Circle, defines Circular Economy as "a manifestation of economic models that highlight business opportunities where cycles rather than linear processes, dominate. It is restorative and regenerative by design and aims to keep products, components, and materials at their highest utility and value at all times". 
According to Het Groene Brein (Brein, 2016) a Foundation in The Netherlands composed of more than 140 scientists working on Circular Economy and sustainable strategies, a circular economy is: "an economic system of closed loops in which raw materials, components and products lose their value as little as possible, renewable energy sources are used and systems thinking is at the core".

In general, we can conclude that the definition of Circular Economy often focusses on two main aspects: the use and life circle of raw materials or the need to change the production systems change. Regarding a product life circle, the following actions are the most common elements on the Circular Economy process: Reduce - Reuse - Recycle. Regarding system change, the following actions are the most common processes: Closed cycles, Renewable energy and systems thinking (Korhonen, Nuur, Feldmann, \& Birkie, 2018).

The European Union has gradually become more and more aware of the soon-to-be-reached limits of the linear economy that has developed across the European territory. This sprung an interest for the design of a new model of economic organization that would assure having enough goods and service as to keep and improve living standards without increasing the consumption of raw materials and the creation of waste, while at the same time helping to avoid new crisis such as that of 2008. However, this entails a necessary change of paradigm from a "growth means prosperity" mentality to one that is "prosperity without growth".

This perspective refers to circular economy. As it was mentioned, a change has to be made to achieve this new economic model, and that is why the European Union has set specific plans and agendas to make this change happen.

The official position of the European Commission on Circular Economy was presented on 17 December 2012 with the publication of a Manifesto for a Resource-Efficient Europe. This document highlights the need to change to a circular economy and society in order to stop the harm made by the crisis. It also focus on the need to reindustrialize Europe to achieve efficient growth and sustainability from the very first paragraph: "In a world with growing pressures on resources and the environment, the EU has no choice but to go for the transition to a resource-efficient and ultimately regenerative circular economy" (Commission, MANIFESTO FOR A RESOURCE-EFFICIENT EUROPE, 2012). According to the European Commission "A circular economy preserves the value added to the products for as long as possible and virtually eliminates waste. The resources are retained within the economy when a product has reached the end of its life, so that they remain in productive use and create further value."

According to the research developed, there is still a lot of work to do in Europe to improve Circular Economy processes and the situation in the different countries differs quite a lot.

In the case of Portugal, it is one of the EU members states that have implemented advanced strategies, roadmaps and action plans for a Circular Economy, in line with the European Commission's ambitions. Circular Economy represents a key option for Portugal's resilience, prosperity and sustainable development, enhancing the efficient use of resources, productivity and competitiveness, generating growth, employment and reducing environmental impacts (e.g., reduction in gas emissions greenhouse gas (GHG)). Now, the vision for Portugal should focus on significant advances in the continuous reuse of the strategically most important materials for the country, in their maximum productive potential (greater financial value and usefulness, for as long as possible), in cycles energized by sources renewable resources, preserving ecosystems and generating jobs and quality of life.

\section{OVERVIEW NATIONAL LEGILATIONS}

The current European Union legislation in terms of circular economy revolves around three topics: waste reduction, substance restriction and the performance of products put on the market (Hughes, 2017). Due to the concern about the environment that starting to arise in the late 1990s and onwards, Europe issued different legislative measures dealing with restricting the emissions that could harm the environment coming from substances or products; reducing the energy consumed; and reducing the amount of material ending up in landfills.

In Portugal, several policies and strategies have been implemented in recent years at the national level that enhance the transition to the circular economy. At the end of 2017, the Government launched the Action Plan for the Circular Economy (PAEC, 2017), which came to establish the priorities, actions and goals that have to be implemented to ensure that Portugal is on the path of 
Circular Economy. This plan presents 7 actions in line with the European pillars of Action for the circular economy, and 3 operational levels: national, sectorial and regional level.

- National level: with dedicated political instruments (e.g. green taxation, voluntary agreements, Portugal 2020 environmental network);

- Sectorial level: which focuses on sectors that are particularly resource intensive (e.g. construction, distribution and logistics, public procurement) or particularly important in the Portuguese business fabric (e.g. tourism, textiles and footwear);

- Regional level: (e.g. networks of industrial symbiosis, circular cities, circular companies), which should be implemented through specific support for the development of solutions (e.g. planning, technological, etc.), through mechanisms designed for this purpose (e.g. Fund Environment, Fund for Innovation, Technology and Circular Economy, Portugal 2020).

\subsection{Conformity with EU standards}

The European Commission has been pushing the idea of a circular economy for years, calling Member States to action. In January 2018, to get a sense of how well countries and the EU are doing in sustainability and Circular Economy, the European Commission published plans to track the economy's circularity in European country. The measurements look at every stage of consumption and post-consumption. Some of the aspects measured are: how much garbage and food waste is produced, how much of that waste is recycled, how much of that recycled material is actually reused, the volume of recyclable materials traded, how many patents are filed related to circular economy, and how many jobs are created linked to CE among other.

POLITICO, the American political journalism company, researched the data for seven of the EU Commission's key metrics and produced a ranking for the $28 \mathrm{EU}$ countries. According to their findings, countries with the highest circular economy scores are Germany, the U.K. and France. They have robust recycling systems and high levels of innovation in circular economy sectors. Bigger countries also tended to rank higher, due in part to the fact that they have larger economies with more private investment and patents. Poland and the Czech Republic also ranked very high in the list, while green Nordic countries ranked lower. Although the Netherlands, Denmark and Sweden rank fairly well in innovation and recycling, their scores are dragged down by high levels of waste and food waste. Meanwhile, the nine countries that produce the least waste are all from Central and Eastern Europe. (Hervey, 18).

The current national political framework in Portugal for the circular economy is the "Action Plan for the Circular Economy in Portugal", approved through the Resolution of the Council of Ministers no. 190-A / 2017, of 23 November. Its objective is to define a national strategy for the circular economy based on the production and disposal of waste and the concepts of reuse, repair and renovation of materials and energy. The «Plan of Action for the Circular Economy in Portugal» is entitled «LEADING THE TRANSITION» and embodies the national strategy aimed at changing the economic paradigm from «linear» to «circular», encompassing a set of seven concrete actions to be fulfilled by 2020 , which aim to accelerate this change, while simultaneously promoting job creation, economic growth, investment and social justice.

\subsubsection{History of CE and developments}

In the early 1990s, when the European Union was first formed, most laws were mainly focused on waste disposal, but a growing concern regarding sustainability and greener economies was starting to develop. In the early years of the EEC, the focus was put on erasing technical barriers that could affect trade within the members in order to create a single market. However, these laws did not form a cohesive whole, as the different Member States had their own regulations. From the 2000s onwards, laws concerning the environmental performance of products were starting to be passed.

On December 2015, the European Commission published its Circular Economy Package, which had a clear objective: closing the loop of product lifecycles by means of approaching economy, product design, manufacturing and consumption in a different way. This package includes an Action Plan with two parts: an introduction dedicated to describing the proposals and an Annex which provides a proposed timescale to agree when the proposed actions should be carried out. (Commission, The European Green Deal, 2019) 
The actions proposed in this Plan aim at providing support to the implementation of circular economy throughout the value chain. The actions that the EU is taken to shift towards a circular economy are the following, as listed in the EU's Circular Economy Action Plan:

- Make sustainable products the norm in the EU;

- Empower consumers and public buyers;

- Focus on the sectors that use most resources and where the potential for circularity is high such as: electronics and ICT; batteries and vehicles; packaging; plastics; textiles; construction and buildings; food; water and nutrients;

- Ensure less waste;

- Make circularity work for people, regions and cities,

- Lead global efforts on circular economy.

The Action Plan for the Circular Economy (PAEC) in Portugal was presented to the Council of Ministers on 8 June. The circular economy, advocated in the Program of the XXI Constitutional Government, is a component of the necessary change of the current economic (linear) paradigm, whose inefficient and productive use of the extracted resources leads to significant economic and environmental losses. The Circular Economy Action Plan is the result of nearly a year of interministerial work among representatives of the Ministries of Science, Technology and Higher Education, the Ministry of Economy, the Ministry of the Environment, and the Ministry of Agriculture, Forestry and Rural Development. In this context, 7 actions were defined that consolidate initiatives in progress by the Government but also introduce complementary initiatives.

\subsubsection{National support structures}

National support structures are regulated by each Member State and are usually linked to each country policies and specific goals.

In Portugal, the national level deals with dedicated political instruments (e.g. green taxation, voluntary agreements, Portugal 2020 environmental network); while the sectoral and regional level deal with things such as networks of industrial symbiosis, circular cities, circular companies. The latter should be implemented through specific support for the development of solutions, and through mechanisms designed for this purpose (e.g. Environmental Fund, Fund for Innovation, Technology and Circular Economy, Portugal 2020).

\subsubsection{National financial support}

The commission has stated in its New Circular Economy Action Plan (p. 19), that it will ensure that its instruments support skill development and job creation. Under the European Social Fund Plus, there will be further investment in education and training systems, lifelong learning as well as social innovation. Relevant EU financing instruments and funds will also be funding necessary investments at regional level in order that all regions benefit from this transition. Cohesion Policy funds will help regions implement circular economy strategies and reinforce their industrial fabric and value chains tailored to each specific region. The InvestEU and the Just Transition Mechanism will be able to support projects focusing on the circular economy.

In addition, the European Commission and the European Investment Bank have made public the result of the public procurement process for the selection of an investment advisor in order to implement and manage the European Circular Bio economy Fund, which will provide access to finance to companies and projects in the field of innovative circular bio economy

In Portugal, the promotion of innovation and investment was also presented as essential, through the following measures: the creation of the European Centre of Excellence for the Efficient Use of Resources to help SMEs to benefit from business opportunities arising from greater resource efficiency; the Horizon 2020 program for 2016-2017 that includes the item "Industry 2020 in the circular economy"; and the creation of a platform, in association with the European Investment Bank and national banks, to support the financing of the circular economy.

\subsubsection{Main difficulties and challenges}

According to Kircherr et al. (2018), there are four types of barriers in the adoption of Circular Economy: the cultural, the regulatory, the market and the technological one. 
One of the biggest obstacles is the cultural barriers (lacking awareness and/or willingness to engage with the circular economy), especially those concerning consumers. Acceptance of Circular Economy mainly depends on consumer's acceptance, so, if consumers prefer new, cheap and disposable products, the market will keep providing them with these products more in line with a linear economy.

In terms of market barriers, low prices of some virgin materials may prevent CE products to be competitive with their linear counterparts. Also, many materials are not recycled because the production of virgin material is cheaper.

Concerning regulatory barriers, there is a lack of "smart regulation" to support this transition and there is a lack of supportive policy frameworks in Member States.

Lastly, regarding technological barriers, it is a prerequisite to have relevant technology implemented to promote the shift to a circular economy. Product design is a key barrier to overcome when adopting circular economy, as well as acquiring the ability to deliver high quality remanufactured products. (Kirchherr, Piscicelli, \& et al., 2018)

In Portugal, the Ministry of the Environment assumes its role of shaping a context that supports the agents in this transition to the circular economy, providing, for example, political instruments that promote the efficient use of resources; and disseminating information on best practices, case studies or financing opportunities. This Ministry also acts through specific interventions in existing financial instruments in order to value initiatives that contribute effectively to EC, namely through sectoral and inter-sectoral projects in this area.

\subsubsection{Good practice in Portugal}

Vintage for a Cause, Porto, Portugal

\section{Website: $h$ ttps://vintageforacause.pt/pages/circular-economy}

Vintage's mission is to manufacture affordable ethical and sustainability clothing inspired by vintage styles. It seeks to create quality clothes, in order to please people and have a reduced ecological footprint. The design process begins with the selection of fabrics rescued from raw material, going through a reduction in water consumption and $\mathrm{CO} 2$ emissions. It also associates its activity with a social project: From Granny to Trendy. In this way, the project seeks to lead and inspire a sustainable way of making fashion.

In order to reduce the negative impact of fashion industry on the environment, Vintage for a cause is redesigning fashion towards closing the loop by using resources that would probably end in the land fields. They prevent new resources extraction and promote water saving and $\mathrm{CO} 2$ reduction. The also promote a full Circular Economy by promoting a sustainable solution for disposing of their clothes: after using a Vintage for a Cause piece, instead of throwing it away, customers can resend it to them, and they will offer a $10 \%$ discount in a new piece of clothing. They also offer customers an upcycling guide and a basic sewing kit. Why buy new clothes if you can reuse a garment or event repair it?

The goal of this initiative is to use sustainable fashion as a mean of personal expression and a powerful tool of social changing while at the same time reducing environmental footprint and minimizing our environmental damage. They are also committed to bring fairer labour to the fashion industry. Thus, they are committed to achieving the following results:

- Reuse $375 \mathrm{Kg}$ of deadstock

- Save 1,4M Lt of water

- Reduce $3456 \mathrm{Kg}$ in CO2 emissions

- 4 From Granny to Trendy Programmes

- 48 workshops $/ 144 \mathrm{~h}$ of upcycling learning

- 1 Fashion show

- 1 Photoshoot

- Reach at least 100 beneficiaries of the programme 


\section{CONCLUSIONS}

Even though Circular Economy is a concept that is gaining support and awareness, there is still a lot to do. The European Union is leading the world's action in this area, and it is pushing forward regulations and setting up goals, but European Member States need to update their regulations and practices in order to reach these goals. Economic benefits must be highlighted to boost the transition to a more sustainable system. Governments, both local and regional, must put more effort and invest in the development of proper legislation that allows companies to make the change towards this type of economy, as well as disseminate the results and all the resources available to reach as many people as possible.

There is a huge need for training both for the general population and companies. The general population need to be aware of what they can do to promote a greener economy and how their actions can have a dire effect in the economy and the planet, and training can help increase people's awareness and produce a change in consumer's habits. At business level, companies need to have trained professionals who can identify the opportunities and needs of the companies and help their transition into a Circular Economy.

Everyone, from the employees, employers, managers, and the population, as well as public institutions and governments need to align their actions and work together, bringing together processes and priorities, in order to boost Circular Economy. This is required if the circular economy is to become an extended reality in our society.

The current national political framework for the circular economy is the "Action Plan for the Circular Economy in Portugal", approved through the Resolution of the Council of Ministers no. 190-A / 2017, of 23 November, whose objective is to define a national strategy for the circular economy based on the production and disposal of waste and the concepts of reuse, repair and renovation of materials and energy.

In order to ensure greater stability in the designation of representatives from different areas and to make the Coordination Group's monitoring of the guidelines provided for in the PAEC more effective, Resolution of the Council of Ministers no. 108/2019, of 2 July, establishes a new composition of the PAEC Coordination Group, which includes representatives from all government areas and is jointly coordinated by the Directorate-General for Economic Activities and the Portuguese Environment Agency, IP

The «Plan of Action for the Circular Economy in Portugal» is entitled «LEADING THE TRANSITION» and embodies the national strategy aimed at changing the economic paradigm from «linear» to «circular», encompassing a set of seven concrete actions to be fulfilled until 2020, which aim to accelerate this change, while simultaneously promoting job creation, economic growth, investment and social justice.

The government and the concerned authorities (local, regional and/or national) should try to make information regarding CE and training more accessible and spread it among their public, as it may improve and boost the implementation of measures related to circular economy in the different companies of the area. In order to boost work in Circular Economy, general awareness and the skills of worker, training should be provided at least in the following areas: Principles of Circular Economy, lifecycle, its values, economic benefit as well as the opportunities and challenges; evolvement of companies and consumers in the circular economy; Ways to approach a transition towards a greener system; Innovation, creativity re-design and systems thinking; Technical aspects regarding specific market/industries; Managerial skills, interpersonal skills; Communication and negotiation skills; Critical analysis; and cooperation, share of information and transfer of information.

\section{ACKNOWLEDGEMENTS}

The CICLO project is funded by the European Commission under the Key Action 202 - Strategic Partnerships for vocational education and training and will last from October 2019 until September 2021.

\section{REFERENCES}

[1] Action Plan for the Circular Economy in Portugal. Available in https://eco.nomia.pt/contents/ficheiros/paec-en-version-4.pdf 
[2] Action Plan for the Circular Economy in Portugal. REPORT 2018. Available in https://eco.nomia.pt/contents/ficheiros/paec-ponto-de-situacao-2018-3-6478.pdf

[3] Brein, H. G. (2016). Het Groene Brein. Retrieved from https://kenniskaarten.hetgroenebrein.nl/en/knowledge-map-circular-economy/what-is-thedefinition-a-circular-economy/

[4] Commission, E. The European Green Deal. pp. 12-11, 2019. Retrieved from https://eurlex.europa.eu/legal-content/EN/TXT/?qid=1588580774040\&uri=CELEX:52019DC0640

[5] Commission, E. MANIFESTO FOR A RESOURCE-EFFICIENT EUROPE. Pp. 12-17, 2012. Retrieved from https://ec.europa.eu/commission/presscorner/detail/en/MEMO_12_989

[6] FCT's thematic research and innovation agenda. Circular Economy. Available in https://www.fct.pt/agendastematicas/ecocirc.phtml.en

[7] Foundation, E. M. Ellen Macarthur Foundation, 2017. Retrieved from https://www.ellenmacarthurfoundation.org/circular-economy/concept

[8] Guide, S. Sustainability Guide, 2017. Retrieved from https://sustainabilityguide.eu/sustainability/circular-economy/

[9] Hervey, G. Politico, pp. 15-23, 2018. Retrieved from Ranking how EU countries do with the circular economy: https://www.politico.eu/article/ranking-how-eu-countries-do-with-the-circulareconomyl

[10] Hughes, R. The EU Circular Economy Package - Life Cycle Thinking to Life Cycle Law? Procedia CIRP, pp. 10-16, 2017.

[11] Kirchherr, J., Piscicelli, L., \& et al. Barriers to the Circular Economy: Evidence From the European Union (EU). Ecological Economics. 2018.

[12] Kirchherr, J., Reike, D., \& Hekkert, M. Conceptualizing the circular economy: An analysis of 114 definitions. Resources, Conservation and Recycling, 221-232, 2017.

[13] Korhonen, J., Nuur, C., Feldmann, A., \& Birkie, S. E. Circular economy as an essentially contested concept. Journal of Cleaner Production , pp. 544-552, 2018.

[14] PAEC. Aprova o Plano de Ação para a Economia Circular em Portugal. Diário da República, 6584-(54) a 6584-(73), 2017.

[15] Parliament, E. Circular economy: definition, importance and benefits, pp- 4-10, 2018. Retrieved from https://www.europarl.europa.eu/news/en/headlines/economy/20151201STO05603/circulareconomy-definition-importance-and-benefits

[16] Taranic, I., Behrens, A., \& Topi, C. Understanding the Circular Economy in Europe, from Resource Efficiency to Sharing Platforms: The CEPS Framework. CEPS Special Report 143, pp. 1-24, 2016. 